\section{Proposal to standardize the nomenclature for paraspinal interfascial plane blocks}

To the editor,

The thoracolumbar interfascial plane (TLIP) block was first described by William Hand and his colleagues in 2015. ${ }^{1}$ Hand's group named the block, 'the novel thoracolumbar interfascial plane block (analogous to the transversus abdominis plane (TAP) block, but intended for the back) which targets the sensory component of the dorsal rami of the thoracolumbar nerves'. ${ }^{1}$ Subsequent studies of other approaches targeting the paraspinal muscle plane yielded new nerve blocks and nomenclature. As a result, we now have a multitude of nerve blocks which have various names coined by the original authors. Given the novelty of these blocks and lack of naming standard, there could be confusion in the literature and the medical community. We propose a systematic approach to organizing the current and future plane blocks that target the dorsal ramus nerve for improved transmission of information and knowledge.

The name 'TLIP block' is confusing as it refers to both the thoracic and lumbar planes. However, Hand et al described the block in the lumbar region and his pilot study refers specifically to lumbar dermatomal coverage. An added complication is the fact that the paraspinal muscles of the cervical (figure 1A), thoracic (figure $1 \mathrm{~B}$ ), and lumbar region (figure 1C) all have different anatomy, and therefore a dorsal ramus block technique is specific to each area.

Additionally, multiple new blocks have been described recently including the modified TLIP (mTLIP) block, ${ }^{2}$ cervical interfascial plane (CIP) block, ${ }^{3}$ multifidus cervicis plane (MCP) block $^{4}$ and intersemispinalis plane (ISP) block, to name a few. These new techniques are very similar in that they all target the dorsal ramus of the spinal nerves and its branches and have been shown to be beneficial for analgesia for spine surgeries. We believe that given their similarity, they should all be part of one block category and should thus be classified as paraspinal interfascial plane (PIP) blocks. Adopting this term will help categorize new blocks, future research into their safety and utility

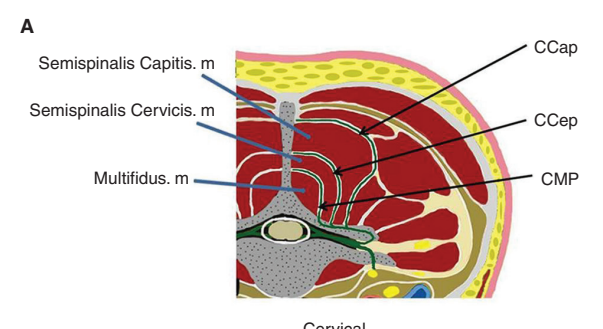

Cervical

as well as teaching and clinical applications. We do not include the erector spinae block in the PIP group of blocks as it could target the ventral ramus in addition to the dorsal ramus, with possible action site being in the paravertebral space. ${ }^{5}$

We believe that naming the cervical, thoracic and lumbar PIP blocks separately would offer more clarity to the anesthesiology community and spur research, learning and discussion of each technique individually. The TAP, serratus anterior plane and erector spinae plane blocks are all plane blocks with wellestablished nomenclature. They are all named for the target muscle fascia and the names are therefore easy to understand. By adopting the tradition of naming plane blocks after the target muscle fascia in PIP blocks, we propose a system which is therefore related. These PIP blocks would include :

1. Cervical multifidus plane (CMP) block (instead of MCP).

2. Cervical semispinalis cervicis plane (CCeP) block (instead of ISP).

3. Cervical semispinalis capitis plane (CCaP) block (instead of CIP).

4. Thoracic multifidus plane (TMP) block (instead of TLIP).

5. Thoracic longissimus plane (TLP) block (instead of mTLIP).

6. Lumbar multifidus plane (LMP) block (instead of TLIP).

7. Lumbar longissimus plane (LLP) block (instead of mTLIP).
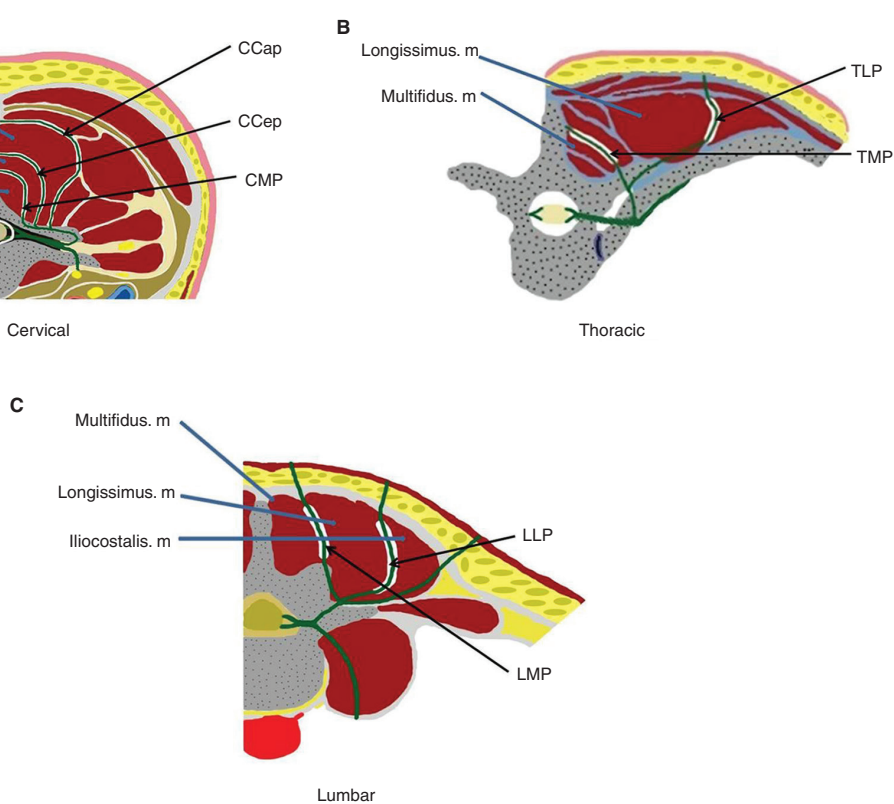

Figure 1 Anatomy of the paraspinal interfasical plane (PIP) at different spine regions. (A) Cervical region. (B) Thoracic region. (C) Lumbar region. Green line: ventral ramus nerve, dorsal ramus nerve and it's branches. $\mathrm{CCaP}$, cervical semispinalis capitis plane; $\mathrm{CCeP}$, cervical semispinalis cervicis plane; CMP, cervical multifidus plane; LLP, lumbar longissimus plane; LMP, lumbar multifidus plane; TLP, thoracic longissimus plane; TMP, thoracic multifidus plane. 
It is our hope that our proposal resonates with the regional anesthesia community and leads to its adoption. It is our belief that this standardized nomenclature will improve the ability of clinicians to differentiate between the PIP blocks. As the number of performed PIP blocks is already substantial and promises to grow, we anticipate that the new nomenclature will facilitate learning how to perform the blocks and will focus research. For example, we have been exploring the LMP/TLIP's effects on neuromonitoring and believe a standard nomenclature would have been helpful. ${ }^{6}$ Ultimately, much information is needed to further define PIP blocks' individual indications and efficacy.

\section{Jeff L. Xu, Victor Tseng}

Department of Anesthesiology, Westchester Medical Center, New York Medical College, Valhalla, New York, USA

Correspondence to Dr Jeff L. Xu, Department of Anesthesiology, Westchester Medical Center/ New York Medical College, Valhalla, NY 10595, USA;

jeff.xu@wmchealth.org

Acknowledgements The authors thank $\mathrm{Mr}$ Alexander Magill for the permission of publishing his digital drawing.

Contributors JLX helped to conceive, design, write and edit the manuscript primarily. VT helped to write and edit the manuscript.

Funding The authors have not declared a specific grant for this research from any funding agency in the public, commercial or not-for-profit sectors.

Competing interests None declared.

Patient consent for publication Not required.

Provenance and peer review Not commissioned; internally peer reviewed.$$
\text { (อ) }
$$$$
\text { OPEN ACCESS }
$$

Open access This is an open access article distributed in accordance with the Creative Commons Attribution Non Commercial (CC BY-NC 4.0) license, which permits others to distribute, remix, adapt, build upon this work non-commercially, and license their derivative works on different terms, provided the original work is properly cited, an indication of whether changes were made, and the use is noncommercial. See: http://creativecommons.org/licenses/ by-nc/4.0\%.

(c) American Society of Regional Anesthesia \& Pain Medicine 2019. Re-use permitted under CC BY-NC. No commercial re-use. Published by BMJ.

\section{Check for updates}

To cite Xu JL, Tseng V. Reg Anesth Pain Med 2019;44:1106-1107.

Received 13 May 2019

Accepted 22 May 2019

Published Online First 19 June 2019

Reg Anesth Pain Med 2019;44:1106-1107.

doi:10.1136/rapm-2019-100696
REFERENCES

1. Hand WR, Taylor JM, Harvey NR, et al. Thoracolumbar interfascial plane (TLIP) block: a pilot study in volunteers. Can J Anesth/J Can Anesth 2015;62:1196-200

2. Ueshima H, Otake H. Clinical efficacy of modified thoracolumbar interfascial plane block. J Clin Anesth 2016;30:74-5

3. Ueshima $H$, Otake $H$. Blocking of multiple posterior branches of cervical nerves using a cervical interfascial plane block. J Clin Anesth 2017;38

4. Yuichi O, Kiyoyasu K. Cervical interfascial plane (CIP) block and multifidus cervicis plane (MCP) block: similarities and tips. J Clin Anesth 2017;41.

5. Tulgar S, Balaban O. Spread of local anesthetic in erector spine plane block at thoracic and lumbar levels. Reg Anesth Pain Med 2019;44:134-5

6. Xu JL, Doherty T, Patel R, et al. Analgesic efficacy of ultrasound-guided modified thoracolumbar interfascial plane block performed with the use of neurophysiology monitoring for postoperative lumbar surgery. J Clin Anesth 2019;52:21-3 